\title{
Stéphane Lacroix, Les islamistes saoudiens. Une insurrection manquée
}

Paris, Presses universitaires de France, coll. « Proche-Orient », 2010, $360 \mathrm{p}$.

\section{Haoues Séniguer}

\section{(2) OpenEdition}

\section{Journals}

Édition électronique

URL : http://journals.openedition.org/assr/22905

DOI : $10.4000 /$ assr.22905

ISSN : $1777-5825$

Éditeur

Éditions de l'EHESS

Édition imprimée

Date de publication : 31 décembre 2011

Pagination : 186

ISBN : 9782713223273

ISSN : 0335-5985

Référence électronique

Haoues Séniguer, «Stéphane Lacroix, Les islamistes saoudiens. Une insurrection manquée », Archives de sciences sociales des religions [En ligne], 156 | octobre-décembre 2011, document 156-60, mis en ligne le 15 février 2012, consulté le 21 septembre 2020. URL : http://journals.openedition.org/assr/ 22905 ; DOI : https://doi.org/10.4000/assr.22905

Ce document a été généré automatiquement le 21 septembre 2020

(C) Archives de sciences sociales des religions 


\section{Stéphane Lacroix, Les islamistes saoudiens. Une insurrection manquée}

Paris, Presses universitaires de France, coll. « Proche-Orient », 2010, $360 \mathrm{p}$.

\section{Haoues Séniguer}

\section{RÉFÉRENCE}

Stéphane Lacroix, Les islamistes saoudiens. Une insurrection manquée, Paris, Presses universitaires de France, coll. « Proche-Orient », 2010, 360 p.

1 L'ouvrage de Stéphane Lacroix a l'insigne mérite de combler un déficit épistémologique patent en matière de connaissance fine et détaillée de l'Arabie Saoudite à l'opposé d'un tintamarre médiatique souvent passionnel. Hormis, peut-être, le livre de Pascal Ménoret (L'énigme saoudienne. Les Saoudiens et le monde, Paris, La Découverte, 2003), il s'agit d'un travail inaugural; du moins, pour ce qui est des travaux francophones éminemment limités, une fois de plus, par rapport à la production anglo-saxonne sur des sujets similaires.

2 Même si l'auteur traite avant tout de l'islamisme, il n'en demeure pas moins que l'ouvrage donne des informations précieuses sur ce qu'il appelle «le champ du pouvoir » saoudien - proposant à cet égard une conceptualisation fort originale à partir de concepts hérités de la sociologie de Pierre Bourdieu -, au sein duquel les champs politique, religieux et économique interagiraient de façon inédite produisant toutes sortes d'effets sur les acteurs sociaux en présence.

3 Issu d'un travail de thèse en vue de l'obtention du doctorat de sciences politiques, l'ouvrage en conserve les traces d'une méthodologie académique rigoureuse explicitée dès les premières pages de l'introduction. Au cours de celle-ci, Stéphane Lacroix opte résolument pour le parti pris méthodologique suivant: laisser de côté «la grille de 
lecture culturelle", sinon culturaliste, pour rendre compte des mobilisations des acteurs, au premier rang desquels les islamistes; ce à partir de la théorie des mouvements sociaux qui prend en compte, loin de tout regard réifiant, la dynamique des acteurs et les contextes dans lesquels celle-ci opère.

Scindée en six parties et traitant d'une période allant grosso modo des années soixantedix à la fin des années quatre-vingt-dix ou début deux mille, la recherche, pour l'essentiel diachronique, prend principalement pour objet d'étude l'islamisme de la Sahwa dont Stéphane Lacroix rappelle, avec beaucoup de détails, la genèse. Il en précise tantôt les continuités tantôt les spécificités par rapport au spectre des Frères musulmans, et en restitue les objectifs même s'ils peuvent, au fil de la lecture, apparaître troubles et confus. À ce titre, l'auteur ne les explicite pas forcément mais en suggérant toutefois qu'il s'agit de « rebelles sans cause ». Que recherchent au juste les militants sahwistes? Le politiste défend la thèse suivante : les partisans de la Sahwa, au plus fort de leur mobilisation jusqu'au milieu des années quatre-vingt-dix, ont enrayé les logiques de champ, leur permettant de mettre en difficulté, temporairement, la royauté et ses agents.

5 Émergente dans les années soixante, la Sahwa, qui littéralement signifierait « réveil » (al-Ṣaḥwa al-islāmiyya : le réveil islamique), offrirait une synthèse originale qui en ferait un modèle d'hybridation du fonds idéologique et la forme organisationnelle des Frères musulmans égyptiens - présents en nombre dans le système éducatif saoudien dès la fin des années cinquante -, et de la pensée religieuse ou dogmatique de Ibn Abd el Wahhab (1703-1792), lequel serait à l'origine du wahhabisme et d'un credo religieux éminemment rigoriste en matière de dogme. La tradition sahwiste serait à l'intersection de la tradition "frériste ", avec ses figures de proue - Hassan al-Banna (1906-1949), Sayyid Qotb (1906-1966), Muhammad Qotb (1919) - et des figures plus locales telles qu'Abd al-Rahman al-Dawsari (1913) qui, entre autres, aurait pensé les fondements théoriques et pratiques de ladite Sahwa. Les Sahwistes seraient ainsi à l'origine d'une pensée politicoreligieuse nouvelle dans la société saoudienne et peutêtre même dans la région.

6 La Sahwa se serait appuyée, dans sa phase de montée en puissance, sur des structures organisationnelles qui intégrèrent précisément la tendance des Frères musulmans et une tendance plus endogène et locale («les Sourouristes»), en contrôlant et en retournant à leur profit, de plus en plus, le système éducatif national alors dominé par des enseignants islamistes égyptiens.

7 Cependant, en dépit de l'alliance qui aurait réuni trois groupes contestataires opposés aux titulaires du pouvoir - «les forces légitimantes » (oulémas sahwistes et oulémas de la génération antérieure ralliée à eux, dits munāșirān) et "forces militantes" (intellectuels sahwistes) -, ceux-ci ne seraient pas parvenus à retourner le champ religieux contre les gouvernants, mais auraient, au contraire, suscité des contre-feux de la part des autorités qui adopteront des mesures de rétention à leur endroit. Les officiels du régime vont parvenir à mobiliser des oulémas, notamment de tendance Ahl al-Hadith (partisans de la tradition prophétique), contre les Sahwistes alors accusés d'importer une idéologie corruptrice des fondements de l'islam sunnite tels que pensés et conceptualisés par les premiers.

8 En définitive, l'apparition des partisans de la Sahwa sur le devant de la scène politicoreligieuse a créé un précédent en Arabie Saoudite, en dépit de l'échec apparent de leur mobilisation, en suscitant, bon gré mal gré, un faisceau de courants 
contestataires intégrant aussi bien des djihadistes que des " islamo-libéraux » partisans désormais de la wasițiyya (modération religieuse) dont l'idée se diffuse également à cette occasion. En effet, celle-ci a mis à nu, publiquement, de nouvelles questions sur la légitimité du pouvoir, l'autonomie de la religion et son statut vis-à-vis du champ institutionnel. La mobilisation sahwiste aurait donné à voir, en quelque sorte, la mainmise totale du pouvoir central, lequel entretiendrait à dessein et de manière totalement instrumentale, les logiques de "sectorisation" des champs politique et religieux. Ce que justement ont cherché à mettre en cause les militants de la Sahwa en tentant de décloisonner les champs en question.

En dépit d'une recherche fouillée et autant informée qu'informative, nous pourrions faire grief à Stéphane Lacroix d'avoir manqué à deux choses : d'une part, sur le fond et d'autre part, sur la forme. D'abord, contrairement à ce qu'il tend à soutenir dès l'entame de la démonstration, l'apparition de la Sahwa et son développement dans la société saoudienne tiendraient autant aux structures sociales préexistantes (les fameuses «structures structurantes" de Pierre Bourdieu) qu'à des facteurs conjoncturels stricto sensu. Le paradigme culturel est, semble-t-il, un peu vite écarté. Ce sont pourtant ces déterminants qui, une fois conjugués, permettent précisément la naissance et l'avènement du mouvement social dans des circonstances objectives qui ne s'inventent pas. Sans le dire explicitement, l'auteur lui-même semble néanmoins le suggérer quelquefois. Ensuite, si S. Lacroix montre bien que les symboles de la contestation sahwiste furent récupérés par les djihadistes, tels que Oussama Ben Laden, n'est-ce pas risqué, au plan conceptuel, d'en faire un quasi sous-groupe de ladite Sawha en risquant de créer des amalgames? Les djihadistes n'en seraient-ils pas plutôt les enfants illégitimes? La rencontre contingente des revendications ne signifierait pas appartenance à une même catégorie aussi symbolique soit-elle. Enfin, sur la forme, compte tenu de la pluralité des noms propres utilisés, pour la plupart inconnus du grand public y compris parfois des chercheurs eux-mêmes, une notice biographique, même sommaire, eût été la bienvenue. Puis, le surcroît d'expressions telles que " sourouristes ", « rejectionnistes », «néo-sahwistes » ou encore "néo-jihadistes » génère le même type de malaise chez le lecteur pouvant gêner sa compréhension et entamer son attention.

Les islamistes saoudiens demeurent un ouvrage de référence dont la lecture est vivement recommandée. En effet, Stéphane Lacroix, à rebours des lectures qui exagèrent le prisme du wahhabisme comme matrice explicative de tous les phénomènes sociaux surgissant en Arabie, rappelle la spécificité d'acteurs dans leur réception singulière de cette tradition religieuse. Ces derniers formeraient un corps hétérogène témoignant une fois de plus, comme l'a démontré dans plusieurs études François Burgat - que l'auteur, étonnamment, ne cite pas - (L'islamisme au Maghreb. La voix du Sud, Karthala, 1988; L'islamisme en face, La Découverte, 2007, $4^{\mathrm{e}}$ éd. mise à jour; L'islamisme à l'heure d'al-Qaïda : réislamisation, modernisation, radicalisations, La Découverte, 2005), de la grande diversité des islamismes, et, partant, du caractère inopérant du label «islamiste » en tant que catégorie analytique pertinente. 